\title{
취약국가의 지원을 위한 글로벌 수준의 정책적 접근: 뉴딜의 경험과 과제
}

목 차

I. 서론

II. 취약국가 개념과 이론적 논의

III. 취약국가의 발전을 위한 뉴딜과 정책목표, 수행방식

IV. 뉴딜의 시범사업의 이행 및 평가

V. 결론 및 정책적 시사점

참고문헌

* 이 연구는 2015년 12 월 한국국제협력단의 “분쟁 및 취약국 지원 현황 분석”의 일부로 수행된 연구임. 연구과제 종료 이후 국제사회의 이론적 논의 및 분석을 보완하였음. 


\section{요 약}

2015년 9월 국제연합(United Nations, UN)은 새로운 세계 개발목표로서 지속가능 한 개발목표 (Sustainable Development Goals, SDGs)를 확정하였다. 특히 SDG16 은 정의와 평화를 유지하고 강건한 제도를 수립하여 사회발전을 추구하는 것을 내용으 로 하고 있는데, 이것은 그동안 국제개발협력에서 가장 어려운 개발의 과제이면서도 가장 시급한 취약국가에 대한 지원의 기본적 방향을 제시하는 것이다. 취약국가는 안보, 행정의 측면에서 국가의 체제가 극도로 붕괴된 나라로서 개발협력 뿐만 아니라 세계 안보에도 매우 심각한 과제로 대두되고 있다.

이 글에서는 취약국가 발전을 위한 뉴딜을 중심으로 국제적인 논의와 시에라리온의 사례를 중심으로 정책추진 상황을 살펴보고, 이를 기초로 한국에 주는 정책적 시사점을 도출하고자 한다. 


\section{I. 서 론}

2015년 9월 국제연합(United Nations, 이하 UN)은 전 세계 국가의 정상들이 모인 총회에서 새천년개발목표(Millenium Development Goals, 이하 MDGs)를 대신할 새로운 세계 개발목

표로서 지속가능개발목표(Sustainable Development Goals, 이하 SDGs)를 확정하였다. $\mathrm{SDGs}$ 는 그동안 분리되어 추진되어오던 개발도상국의 빈곤퇴치 등 사회·경제발전 노력과 지구 환경을 보호하는 지속가능한 발전을 노력을 통합한다는 커다란 방향을 제시하였다. 이와 더불어 그동안 국제사회의 개발목표에서 명시적으로 제시하지 않았던 사회정의, 평등, 구조적 개혁 등과 같은 매우 정치적인 정책목표들 글로벌 개발목표에 포함하여 추진한다는 점에서 MDGs와 중요한 차별성을 갖는다.

특히 SDG16은 정의와 평화를 유지하고 강건한 제도를 수립하여 사회발전을 추구하는 것을 내용으로 하고 있는데, 이것은 그동안 국제개발협력에서 가장 어려운 개발의 과제이면서도 가장 시급한 취약국가에 대한 지원의 기본적 방향을 제시하는 것이다. 취약국가는 갈등과 분쟁 과 같은 다양한 위협요인으로 인하여 국가의 체제가 매우 취약한 상태에 놓여 있거나, 실질적으 로 와해되어 있는 상태의 국가들을 의미한다. UN이나 경제협력개발기구(Organization for Economic Cooperation and Development, 이하 $\mathrm{OECD}$ ) 등과 같은 국제기구들도 앞으로 $\mathrm{SDGs}$ 가 성공적으로 개발목표를 달성하는데 있어서 평화구축과 강건한 제도 형성을 통해 취약 국가에서 얼마나 성과를 산출하는지가 핵심적인 요소로 작용할 것으로 판단하고 있다.

사실 취약국가에 대한 정책적 관심은 국제사회에서 상당히 오랫동안 지속되어 왔다. 경제적 관점에서 최빈국(Least Development Countries, LDCs)으로 다루어져 오기도 했으며, 국제 금융기구들은 높은 부채와 이로 인한 국제금융위기라는 관점에서 고채무국(Highly Indebted Countries, $\mathrm{HICs}$ )으로 분류하기도 하였다. 이러한 접근은 주로 경제적 측면에서 해당 국가의 정책적 과제를 파악하는 것이었다. 그런데 2002년 미국에 대한 9·11 테러 이후 갈등과 분쟁으로 국가의 안보 및 행정체제가 극도로 붕괴된 국가들에 대한 관심이 더욱 증폭되었으며, 이러한 국가들을 묶어서 취약국가(fragile state 혹은 Fragile and Conflict-Affected States, $\mathrm{FCAS}$ )로 부르고 있다. 따라서 이들 국가가 직면한 문제 및 개발의 과제를 경제적 측면뿐만 아니라 정치, 행정, 안보적 관점에서 파악하고자 하는 것이다.

9·11 이후에도 세계는 지속적으로 테러의 공격으로 고통을 받고 있는데 2015년 프랑스 파리 에서 테러를 비롯해 최근 영국 런던 및 맨체스터 등에서 테러 공격이 자행되었다. 이러한 테러 공격은 전 세계가 다양한 갈등과 분쟁에 부딪혀 적절한 해결책을 찾아내지 못하고 있다는 것을 
의미하는 한편, 여러 취약국가에서 안보 및 치안이 극도로 불안한 상황에서 테러단체의 본거지 로 활용되는 것을 적절히 통제하지 못하면 테러의 위협을 차단하기 어렵다는 것을 보여준다. 이와 더불어 현재까지 지속되는 시리아 내전과 이로 인해 발생한 정치적 공백 속에서 이슬람 단체가 유사국가(quasi-state)로서 모습을 갖추면서 적극적으로 테러를 지원하는 상황에 이 르고 있다.

이러한 국제사회의 안보와 직결되는 취약국가의 문제는 보다 근본적으로 세계의 많은 개발도 상국이 사회·경제적 발전을 효과적으로 성취하지 못했다는 점을 방증하는 것이다. 세계의 평화 를 수호하고 취약국가에서 분쟁과 갈등을 극복하여 사회·경제적 발전을 이루기 위해서는 이들 국가 직면한 정치적 갈등을 효과적으로 해결하고 국민들에게 필요한 공공서비스를 제공하는 행정 능력을 회복하는 것이 매우 시급하다고 판단된다. 이러한 시각에서 지난 10 여 년간 세계의 주요 공여국과 기관들은 취약국가의 개발협력 과제에 대해 다양한 논의와 정책을 시도해왔으며, 한국도 취약국가에 대한 다각적 지원을 해온 것이 사실이다. 특히 지난 2011년 부산에서 개최된 국제개발원조 정책에 관한 고위급 회담에서 취약국가들과 함께 $\mathrm{OECD}$ 의 '분쟁 및 취약성에 관한 국제네트워크(International Network on Conflict and Fragility, 이하 INCAF)'가 중심이 되어 '평화구축과 국가건설을 위한 국제대화체(International Dialogue on Peacebuilding, 이하 IDPS)'를 만들었는데, 여기서 '취약국가에 대한 협력을 위한 새로운 대안(New Deal for Engagement in Fragile State, 이하 뉴딜)에 합의하고 이를 추진하기로 하였다. 이렇게 볼 때 취약국가의 개발을 도모하기 위한 국제사회의 노력에서 한국이 지속적으로 역할을 수행하는 것은 매우 의미 있는 일이라고 하겠다.

뉴딜 이후 $\mathrm{OECD}$ 개발원조위원회(Development Assistance Committee, 이하 DAC)와 $\mathrm{INCAF}$ 와 IDPS를 중심으로 취약국가의 발전을 위한 정책적 논의 및 수단개발 그리고 취약국 가들이 구성한 g7+와 공동의 노력을 취하고 있다. 이러한 뉴딜을 중심으로 한 취약국가 발전을 위한 국제사회의 노력을 살펴보고 그 결과에 대해 평가해 보는 것은 국제개발협력 정책에 중요 한 과제라고 판단된다. 이러한 객관적 검토를 통해 향후 정책방향 및 수단에 대한 모색하는 것이 필요하며, 이러한 맥락에서 이글에서는 취약국가에 대한 국제사회의 논의, 정책추진 과정 및 결과에 대해 분석하기로 한다. 특히 시에라리온의 뉴딜 사업을 사례를 소개하고 이에 대하여 뉴딜에서의 취약국 개입방식(FOCUS)과 뉴딜에서의 취약국 개입원칙(TRUST)의 관점에서 지금까지 진행된 정책에 대해 과정 평가를 시도하기로 한다. 이와 더불어 향후 한국의 정책에 주는 시사점을 도출하고자 한다. 


\section{II. 취약국가 개념과 이론적 논의}

취약국가에 대한 개념과 이론은 여전히 명확히 정리되지 않고 있는 것이 사실이다. 취약 (fragile)한 국가는 다양한 외부의 위협으로부터 취약성을 내포하고 있으나 여전히 국가 운영에 필요한 제도들이 작동하고 있는 국가로 이해될 수 있다. 그러나 국제개발협력 현장과 학계에서 사용되는 의미를 추적해 보면 단순히 취약성을 내포한 국가뿐만 아니라 국가로서 적정한 기능을 수행하지 못하는 실패한 국가와 분쟁과 갈등으로 인해 심각한 도전에 처한 국가 등을 포함해서 사용하기도 한다. 취약국가에 대한 학술적 정의와 이에 대한 기존 논의을 심도있게 검토할 필요가 있다.

먼저 Bertoli \& Ticci(2012)의 연구는 취약국가에 대한 정의가 두 가지 관점에서 분류될 수 있다고 보았다. 첫째, 결과의 시각에서 취약국가에 대한 정의를 내리는 것이다. 이러한 정의 는 MDGs 등의 개발목표를 달성하기 위한 다양한 성과지표들을 비교하여 그 가운데 개발의 효과성이 낮은 국가들을 취약국가로 분류하는 것이다. 이들 국가는 많은 공적원조를 지원하여도 그 효과가 뚜렷하지 않아 원조 배분에서 소외되기 쉽다는 지적도 있다(Dollar \& Levin, 2006). 그런데 이렇게 결과에 초점을 맞추어 취약국가를 정의하게 되면 개발과정에 어려움을 겪고 있는 국가를 식별할 수 있지만, 실제로 그것이 어떠한 원인에 의하여 발생하였는지 알 수 없다는 단점이 있다.

두 번째 접근방법은 정책 결정 및 집행과정의 관점에서 취약국가를 정의하는 것이다. 이러한 관점은 취약성이 나타나게 된 원인에 초점을 맞추어서 취약국가를 정의하고 분석하여야 취약성 을 극복할 수 있다는 시각에 근거하고 있다. Engberg-Pederson(2008)에 따르면 취약성은 공식적 의사 결정과 공공서비스 제공과정에서 책임성, 투명성, 예측 가능성이 매우 낮고, 정책적 불확실성이 높은 것으로 정의될 수 있다. 이러한 제도의 취약성이 개발의 지체를 가져온다는 것이다.

보다 구체적으로 취약성의 원인에 관해 분석한 연구를 보면 식민경험, 내부분쟁 및 갈등과 같은 역사-사회적 요인과 더불어 불평등, 빈곤, 교육 등과 같은 사회적 요인, 천연자원, 소규모 섬 등과 같은 지리적 요인 등이 취약국가의 취약성의 원인으로 작용하고 있음을 지적하고 있다 (Feeny, Posso \& Ragan-Beasley, 2015). 이렇게 취약국가를 원인의 측면에서 정의하게 되면 분명하게 나타나는 사실은 취약성의 원인은 다양하게 존재하고 있으며, 따라서 취약성의 극복을 위해서는 취약성의 원인에 맞는 정책적 처방이 필요하다는 것을 알 수 있다. 이와 더불어 취약국가의 리스트를 작성하는 등 취약국가를 식별하는 것으로는 취약국가에 대한 적절한 정책 
을 개발하는데 충분할 수 없다는 지적이 제기될 수 있다(OECD, 2015).

이렇게 취약국가는 결과의 측면에서 노출되는 취약성과 취약성을 발생시키는 원인의 측면에 서 살펴볼 수 있다. 이러한 두 가지 측면을 통합하여 보면, 취약국가는 국민에게 공공서비스를 제공할 능력이 없는 국가로서 정치적 측면에서 권위와 정당성의 부족, 행정적 측면에서 행정 능력의 부족, 안전의 측면에서 치안과 안보의 불안이 심각한 수준에 이른 국가로 정의할 수 있다(권혁주 외., 2011) 물론 어떤 취약국가가 이 모든 면에서 취약성을 노정하지는 않으며, 특정의 측면에서 취약성을 갖는 경우가 일반적이다. 취약성의 원인도 국가의 관점에서 다양하게 분류될 수 있다. 그러나 <표 $1>$ 에서 보는 바와 같이 수단과 콩고와 같은 국가들은 정치, 행정, 안전의 측면에서 모두 높은 취약성을 보이고 있다.

〈표 1〉 취약성 기준별 취약국 순위

\begin{tabular}{c|c|c|c}
\hline & 정치(P) & 국가행정(G) & 안전(S) \\
\hline 1 & 아프가니스탄 & 코모로 & 이라크 \\
\hline 2 & 이라크 & 에티오피아 & 소말리아 \\
\hline 3 & 수단 & 지부티 & 아프가니스탄 \\
\hline 4 & 소말리아 & 콩고(DRC) & 수단 \\
\hline 5 & 콩고(DRC) & 수단 & 파키스탄 \\
\hline 6 & 아이티 & 시에라리온 & 차드 \\
\hline 7 & 네팔 & 서안지구와 가자지구 & 콩고(DRC) \\
\hline 8 & 부룬디 & 라이베리아 & 나이지리아 \\
\hline 9 & 에리트레아 & 소말리아 & 중앙아프리카공화국 \\
\hline 10 & 서안지구와 가자지구 & 부룬디 & 짐바브웨 \\
\hline 11 & 미얀마 & 아이티 & 미얀마 \\
\hline 12 & 라이베리아 & 차드 & 부룬디 \\
\hline 13 & 에티오피아 & 에리트레아 & 예멘 \\
\hline 14 & 코트디부아르 & 파키스탄 & 에티오피아 \\
\hline 15 & 나이지리아 & 토고 & 케냐 \\
\hline 16 & 차드 & 예멘 & 코트디부아르 \\
\hline 17 & 앙골라 & 기니비사우 & 아이티 \\
\hline 18 & 파키스탄 & 기니 & 쿠간다 \\
\hline 19 & 토고 & 아프가니스탄 & \\
\hline
\end{tabular}

출처: 권혁주 외 (2011) 
특히 대부분의 취약국가들이 다른 개발도상국과 비교할 때, 개발의 성과가 미약하고 MDGs 달성에 있어서도 커다란 진척을 보이지 못하였기 때문에, 이러한 지역에서 개발성과를 달성하려 면 취약국가의 독특한 상황을 고려한 정책접근이 필요하다는 시각이 제기되어 왔다. 이러한 문제의식과 궤를 같이하여 $\mathrm{OECD} \mathrm{DAC은} \mathrm{취약국가의} \mathrm{발전을} \mathrm{효과적으로} \mathrm{추진하기} \mathrm{위해} 2007$ 년 '취약국가에 대한 국제사회의 모범적인 개입원칙' 등이 이미 제시한 바 있다 (<표 2> 참조). 이것은 취약국가와 개발협력을 추진함에 있어서 고려해야 할 사항을 제시한 것으로 이것을 기본으로 각각의 취약국가의 분쟁과 취약상황을 고려하여 진행하는 것이 바람직하다는 규범적 지침이라고 할 수 있다.

〈표 2〉 취약국에 대한 국제사회의 10 가지 모범적인 개입원칙

(Principles for Good International Engagement in Fragile States, FSPs)

1) 취약국가가 처한 상황을 먼저 살필 것

2) 국제사회의 개입으로 피해가 발생하지 않도록 할 것

3) 국가건설을 중심 목적으로 할 것

4) 분쟁예방을 최우선으로 할 것

5) 정치, 안보, 개발 목적들이 서로 연결돼 있다는 것을 인지할 것

6) 포괄적이고 안정적인 사회를 위한 토대로서 비차별 원칙을 장려할 것

7) 여러 다른 방식과 맥락에서 현지의 우선순위를 조정할 것

8) 국제 행위자들 사이에 실질적인 조정 메커니즘에 합의할 것

9) 신속히 행동할 것, 하지만 성공할 수 있도록 충분히 오래 개입할 것

10) 배제되는 사람들(원조 고아들)이 없도록 할 것

출처: OECD (2007)

이와 함께 취약국가 개발협력에서 강조해야 할 점은 범국가적 접근(whole-of-government) 이다. 범국가적 접근이란 어떤 취약국가를 지원함에 있어서 해당 공여국의 다양한 관련 기관이 서로 원활한 협력과 조정을 통해 범국가적으로 정책 방향을 조화시킨다는 것이다(배재현 외., 2010). 갈등과 분쟁 그리고 내전과 같은 상황이 발생하기 쉬운 취약국가의 특성상 개발협력의 전문기관뿐만 아니라 군사적 측면에서 군사적 개입이 이루어지는 경우가 있기도 하고, 외교 문제를 다루는 외교부와 테러 집단에 대한 정보를 국가 정보부 등 다양한 정부기관이 현장에서 정책을 수행하는 경우가 비일비재하다. 이러한 과정에서 해당 공여국의 정부기관이 서로 다른 방향의 정책을 추진하여 혼선을 초래하거나, 그로 인해 취약국가에서 개발협력이 실패로 돌아가 는 경우가 발생하기도 있다. 이러한 맥락에서 범국가적 정책조정을 위한 노력이 매우 긴요함을 강조하는 것이다.

그런데 $\mathrm{OECD}$ 를 비롯해서 국제기구와 공여국들의 취약국가에 대한 정책적 노력은 주로 
$\mathrm{OECD}-\mathrm{DAC}$ 을 중심으로 개발된 공여국가의 관점의 접근방법으로서, 실질적으로 협력의 파트 너인 취약국가의 목소리가 반영된 것은 아니었다. 이러한 공여국 중심의 취약국가 논의에 취약 국가로 인식되는 국가들이 문제를 제기하기 시작했다. 2008년 제 3차 원조효과성 제고를 위한 고위급 회담(High-level Forum on Aid Effectiveness, HLF-3)에서 취약국가로 분류된 국 가들이 자신들이 관련된 개발협력 정책에 대해 구체적으로 목소리를 내고 반영할 수 있는 국제적 협의체가 필요하다는 것을 주장하였다(IDPS, 2011a). 이렇게 하여 2008년 12 월 이미 존재하고 있던 갈등-평화와 개발협력 네트워크(Network on Conflict, Peace and Development Cooperation, $\mathrm{CPDC}$ )와 취약국가그룹(Fragile State Group, FSG)을 합하여 INCAF를 구 성하였다. 이와 함께 취약국가들이 스스로 하나의 국제적 그룹을 만들어 이를 $\mathrm{g} 7+$ 라고 부르기 시작했는데 1$)$, 이들 국가와 $\mathrm{OECD} \mathrm{DAC}$ 의 INCAF가 평화구축을 위하여 IDPS를 만들어 운영 하게 되었다.

IDPS는 제 1회 회의를 2010년 4월 동티모르 딜리에서 개최하였는데, 이 회의에서 딜리 선언을 채택하였다(IDPS, 2010a). 여기서 IDPS는 평화구축과 국가건설을 위한 목표에 대해 논의하기 시작했다. 이어 2011년 6월 라이베리아 몬로비아에서 개최된 제 2회 IDPS 회의에서 보다 구체적으로 취약국가에서 평화구축과 국가건설의 목표들을 명확히 제시하였다 $(<$ 표 $3>$ 참조).

〈표 3〉 5 개의 평화구축 및 국가건설 목표들

(Peacebuilding and Statebuilding Goals, PSGs)
1) 정당한 정치(legitimate politics) : 포용적인 정치적 합의와 분쟁 해결 방식 배양
2) 안보(security) : 국민 안보 확립 및 강화
3) 정의(justice) : 불공정 해소 및 국민의 사법 접근권 증진
4) 경제적 토대(economic foundations) : 일자리 창출과 생활환경 개선
5) 조세 수입 및 서비스(revenues and services) : 조세 수입 관리 및 책임 있고 공정한 사회서비스 전달 역량 구축

출처: IDPS (2011b)

$\mathrm{IDPS}$ 가 제시한 취약국가의 평화구축 및 국가건설의 목표들은 취약국가의 미약한 개발성과 가 어떠한 원인에서 비롯되는가를 살펴보고 이에 대해 구체적인 대안을 개발목표의 형식으로 제시했다는 데 의의가 있다. 새천년 개발목표와 더불어 취약국가에게 독특하게 요구되는 목표를 설정하는 시도라고 평가된다. 구체적으로 평화구축 및 국가건설 목표는 정치, 행정, 안보 분야에

1) 아프가니스탄, 부룬디, 중앙아프리카 공화국, 차드, 코모로스, 코트디부아르, 콩고민주공화국, 기니, 기니비사우, 아이티, 라이베리아, 파푸아뉴기니, 상투메프린시페, 시에라리온, 소말리아, 솔로몬제도, 남수단, 동티모르, 토고, 예멘 등이 $\mathrm{g} 7+$ 에 가입하고 있다. 
서 취약성을 지적하고 이를 극복하기 위한 정책 방향과 목표를 제시하고 있다.

지금까지 취약국가에 대한 개념 정의와 취약국가의 식별과 취약성의 원인을 살펴보면서 개념 적, 이론적 내용을 살펴보았다. 이와 함께 취약국가에서 개발협력을 하는데 있어서 필요한 접근 방식에 대한 국제사회의 논의와 함께 취약국가에게 필요한 평화구축 및 국가건설을 위한 목표를 수립하게 된 이론적 배경을 살펴보았다. 결론적으로 취약국가의 개발을 위해서는 지금까지 경제, 사회발전을 중심으로 한 개발방식과 더불어 정치, 행정, 안보의 과제를 중요하게 포함시켜 야 한다는 점이다.

\section{제 I 장}




\section{III. 취약국가의 발전을 위한 뉴딜과 정책목표, 수행방식}

취약국가들과 $\mathrm{OECD}-\mathrm{DAC}$ 의 협의기구인 IDPS의 제 2차 회의에서 취약국가 발전을 위한 몬로비아 로드맵이 만들어졌다. 이를 기초로 부산에서 개최된 제 4 차 원조효과성 제고를 위한 고위급회담(High-level Forum on Aid Effectiveness, HLF-4)에서 뉴딜이 국제사회의 승 인을 받게 되었다. 뉴딜은 국제개발협력에서 취약국가에 대한 지원의 새로운 방향성을 제시하게 되었다는 의의가 있으며 기존의 전략과는 커다란 차별성을 갖는다(Nussbaum et al., 2012).

첫째, 취약국가의 개발협력 성과가 미미하게 나타남에 따라 공여국을 중심으로 원조에 대한 피로현상이 발생하기 시작하였는데, 이로 인해 취약국가에 대한 지원이 축소되고 이에 따라 취약국가의 문제는 더욱 악화될 위험에 직면하고 있었다. 이러한 시기에 취약국가에 대한 새로 운 방식의 개발협력을 제시하여 취약국가에 대한 국제사회의 노력을 다시 한번 동원하는 계기가 되었다는 점이다.

둘째, 뉴딜은 취약국가에서 국내의 협력 대상자를 명확히 하는 계기가 되었다. 취약국가들은 정치적 불안과 안보적 위협으로 개발협력을 추진할 때 함께할 국내의 파트너가 뚜렷하지 않아 많은 혼선을 초래하는 상황이었다. 이러한 상황에서 공여기관을 국내 협력 기관을 찾는데 어려 움을 겪었다. 또한 파트너를 잘 못 선정하는 경우 오히려 정치적 혼란을 초래하고 피해를 야기하는 경우가 있었다. 이로 인해 $\mathrm{OECD}$ 는 공여국이 분쟁 및 취약국의 국가체제구축(statebuilding)과 평화구축(peace-building)에 참여함에 있어서 분쟁과 갈등의 예방 및 방지에 우선순위를 부여하고, 수원국의 상황을 고려한 범정부적 접근이 필요하다는 원칙을 제시했던 것이다. 또한 취약국가에 대한 개입은 일관성 있고 신속하지만 지속가능해야 하며 비의도적인 악영향을 최소화해야 한다는 "do no harm" 원칙을 강조하고 있다(권혁주 외, 2010; 배재현·노 우영, 2012 참조). 이러한 관점에서 볼 때 뉴딜을 통해 취약국가의 국내 책임기관을 명확히 하고, 혼선을 해결할 수 있어 결과적으로 개발 효과성을 높이는 계기를 마련하는 의의가 있다고 평가할 수 있다.

셋째, 뉴딜을 통해 취약국가 분류와 관련한 외교적 문제를 회피할 수 있게 되었다. 취약국가에 대한 개발협력을 수행함에 있어서 해당 취약국가의 특성을 고려한 정책을 추진하는 것이 외교적 문제를 야기해 온 것이 사실이다. 다시 말해 해당 국가들이 '분쟁 및 취약국가'라는 명칭 자체에 대한 거부감을 가지고 있었으며, 이것은 외교적 문제를 야기했고, 취약국가 문제를 다루는 데 주요 걸림돌이 되었다. 이러한 거부감을 우려하여 공여국은 취약성에 대해 애매모호하게 정의를 내리는 경향이 있었고, 따라서 같은 기관 내에서도 합의가 존재하기가 어려웠으며 그로 인해 
취약국가 개입 채널의 복잡성이 높아지고 정책적 일관성이 낮아지게 되었다(Grimm, 2014). 이러한 문제점을 고려해 볼 때, $\mathrm{g} 7+$ 에 국가들이 스스로를 취약국가의 그룹으로 인정하고 적극 적으로 나서서 협력하는 것은 커다란 전기가 되었다고 평가된다.

〈표 4〉PSGs 공통지표 초안

\begin{tabular}{|c|c|c|}
\hline 목표 & 세부항목 & 세부지표 \\
\hline \multirow{3}{*}{$\begin{array}{l}\text { 정당한 } \\
\text { 정치 }\end{array}$} & $\begin{array}{l}\text { 정치체제의 } \\
\text { 대표성 }\end{array}$ & $\begin{array}{l}\text { 1) 주요 국가 제도에서의 대표들의 다양성 } \\
\text { 2) 정부 내에서 대표의 인식 }\end{array}$ \\
\hline & 정치 참여 & $\begin{array}{l}\text { 3) 선거에 대한 참여와 만족 } \\
\text { 4) 정치 과정에의 참여와 지방 수준에서의 시민 참여 }\end{array}$ \\
\hline & 사회적 관계 & $\begin{array}{l}\text { 5) 폭력을 발생시키는 집단 간 논쟁의 수 } \\
\text { 6) 사회 내의 다양한 집단을 포함하는 공동 계획(initiatives)의 수 }\end{array}$ \\
\hline \multirow{3}{*}{ 안보 } & 안보 상황 & $\begin{array}{l}\text { 1) 인구 } 100,000 \text { 명당 폭력으로 사망한 사람의 수 } \\
\text { 2) 분쟁과 폭력으로 발생한 정치 난민 및 내부적 이동(displacement) } \\
\text { 3) 성폭력 발생 정도 } \\
\text { 4) 안전하다고 느끼는 사람의 비율(\%) } \\
\text { 5) 외부 영향에 의해 사망한 사람의 수 }\end{array}$ \\
\hline & 안보 제도의 성과 & 6) 안보 제도들의 성과에 대한 대중의 신뢰 \\
\hline & 안보 제도의 역량 & $\begin{array}{l}\text { 7) (proposed) 영토 내의 경찰(치안 제도) 및 국가 안보의 존재 또는 비국가 } \\
\text { 무장 집단의 존재 } \\
\text { 8) 경찰 인력 내의 월급 지급 빈도 } \\
\text { 9) (proposed) 경찰 인력 내의 인적 자원의 질 }\end{array}$ \\
\hline \multirow{3}{*}{ 정의 } & $\begin{array}{l}\text { 사법 제도의 } \\
\text { 성과와 독립성 }\end{array}$ & $\begin{array}{l}\text { 1) 인권 메커니즘 등을 포함한 (공적 및 관습적) 사법 제도들의 성과에 } \\
\text { 대한 대중의 신뢰 } \\
\text { 2) 당국에 범죄를 보고한 피해자의 비율(\%) } \\
\text { 3) (proposed) 사법 제도의 독립성 - 판사의 정년 }\end{array}$ \\
\hline & 사법 제도의 역량 & $\begin{array}{l}\text { 4) 미결구금의 정도 } \\
\text { 5) 경찰 관련 문서의 변경 비율(\%) / 검찰에 의해 수락된 사건들의 비율(\%) }\end{array}$ \\
\hline & $\begin{array}{l}\text { 사법에 대한 } \\
\text { 접근성 }\end{array}$ & $\begin{array}{l}\text { 6) 인권 및 법적 대표성을 포함하여 시민들의 법의식 / 이에 대한 지원 } \\
\text { 7) 공적 및 관습적 사법 제도들과 대중과의 물리적 근접성 }\end{array}$ \\
\hline \multirow{3}{*}{$\begin{array}{l}\text { 경제적 } \\
\text { 토대 }\end{array}$} & $\begin{array}{l}\text { 생산적 자원 및 } \\
\text { 성장에 대한 전망 }\end{array}$ & $\begin{array}{l}\text { 1) 이용 가능하고 서비스 받을 수 있는 수송 네트워크, 커뮤니케이션, 물, } \\
\text { 에너지에 접근 가능한 인구 } \\
\text { 2) 지역 간 소득 불평등 }\end{array}$ \\
\hline & 고용 및 생활환경 & $\begin{array}{l}\text { 3) 실업이거나 능력 이하의 일을 하는 노동자의 비율(\%) } \\
\text { 4) 과거 3개월간의 식량 가격의 변동률(\%) }\end{array}$ \\
\hline & 천연자원 관리 & $\begin{array}{l}\text { 5) 천연자원 관리를 위한 규제적 프레임워크의 존재 여부 및 집행 } \\
\text { 6) 천연자원으로부터의 수익의 공평한 사용에 대한 인식 }\end{array}$ \\
\hline \multirow{3}{*}{$\begin{array}{l}\text { 세입과 } \\
\text { 서비스 }\end{array}$} & 세입관리 & $\begin{array}{l}\text { 1) 세수를 거두기 위한 국가 독점 및 역량, 영토 내의 관세 및 요금 } \\
\text { 2) GDP 대비 세입 }\end{array}$ \\
\hline & 공공행정 & $\begin{array}{l}\text { 3) 공공 재정관리의 질 및 내부 감사 메커니즘 } \\
\text { 4) 공공서비스를 이용하거나 공무원과 상호작용할 때 뇌물 제공을 보고한 } \\
\text { 인구의 비율(\%) }\end{array}$ \\
\hline & 서비스 전달 & $\begin{array}{l}\text { 5) 서비스 분배 } \\
6) \text { 서비스 전달에 대한 대중의 만족도 }\end{array}$ \\
\hline
\end{tabular}

출처: IDPS (2013) 
이렇게 공여국과 취약국가들이 공동의 노력을 취하는 뉴딜에 대한 의견이 모이자 보다 구체 적으로 평화와 국가체제 구축을 위한 목표를 설정하는 것으로 논의가 발전되었다. <표 4>에서 제시된 바와 같이 앞서 합의된 평화와 국가구축을 위한 5 가지 기본 방향에 각각 세부적인 항목과 구체적인 세부지표를 설정하였는데, 이와 같은 결과는 2013년 워싱턴에서 개최된 제4차 $\mathrm{IDPS}$ 회의에서 나온 것이었다.

취약국가 개발을 위한 구체적인 목표와 세부지표와 함께 주목해야 할 점은 이에 대한 집행방 식과 집행원칙이다. 이미 지적한 바와 같이 취약국가는 각각의 취약성이 독특하기 때문에 이에 대한 분석과 그에 따른 집행전략이 필요하기 때문이다. 또한 취약국가의 복잡한 사회갈등 속에서 개발협력을 진행하기 위해서는 명확한 개입의 원칙이 필요하게 되는데, 이러한 필요에 대응하여 개입방식과 원칙에 대해 제시한 것이 FOCUS와 TRUST이다(IDPS, 2011a).

\section{〈표 5〉 뉴딜에서의 취약국 개입방식}
1) 취약성 평가 (Fragility assessment)
2) 하나의 비전 및 하나의 계획 (One vision, one plan)
3) 이행협약 (Compact)
4) 모니터링에 PSGs를 활용 (Use PSGs to monitor)
5) 정치적 대화 및 리더십 지원 (Support political debate and leadership)

(출처: IDPS, 2011a)

먼저 협력을 수행함에 있어서 취약성 평가(fragility assessment)를 먼저 시작해야 한다는 것이다. 취약성 평가는 취약국가와 공여국이 함께 취약국가의 취약성을 평가하는 과정이다. 이를 통하여 취약국가의 독특한 취약성을 파악하며 이 과정에서 취약국가의 요구도 충분히 수렴한다. 이로써 공여국의 입장에서는 취약국가 지원에서 취약국가의 정책적 필요성을 존중할 수 있고 집행에 있어 위험부담도 경감하는 계기가 될 수 있다.

취약성 평가를 통해 국별 PSG 지표가 구체적으로 설정되고, 양 당사자들 간에 합의가 되어 협약이 체결되었지만, 이 목표가 취약국의 국가개발과 연계되지 않는다면 실효성이 없게 될 것이다. One vision, one plan 원칙은 이같이 국별 PSG 목표와 지표가 국가의 중·장기 정책 방향과 연계되어야 하고, 취약국가의 주요 이해관계자들과의 협의하에 조정, 검토되어야 한다는 점을 강조하는 것이다. 또한, 공여국과 해당 파트너 국가 사이에 밀접한 협의, 협상, 토론을 통한 협약(compact)을 맺을 수 있는 프레임을 제공하였다. 더불어 PSG 지표 달성상황에 대한 모니터링과 국가, 지역, 글로벌 수준의 정치적 대화와 리더십을 지원하고, 이때 청년과 여성의 참여를 강조하고 있다. 
〈표 6〉 뉴딜에서의 취약국 개입원칙(TRUST)

1) 취약성 평가 (Fragility assessment)

2) 하나의 비전 및 하나의 계획 (One vision, one plan)

3) 이행협약 (Compact)

4) 모니터링에 PSGs를 활용 (Use PSGs to monitor)

5) 정치적 대화 및 리더십 지원 (Support political debate and leadership)

출처: IDPS (2011b)

한편 뉴딜에서는 취약국가에서 평화구축과 국가 발전을 위한 목표를 추진함에 있어서 지켜야

할 원칙도 제시되었다. 이것은 <표 6>과 같이 TRUST로 요약되는데 사업을 수행하는데 있어

서 투명성을 지켜야 하며 예상되는 위험에 대해 함께 대응하고 책임진다는 것이다. 이와 함께 취약국 역량 강화와 제도 발전을 위해 취약국가의 제도를 활용하고 공무원 등과 같은 주요 당사자의 역량 개발에 힘써야 한다는 것이다. 이점은 그동안 개발협력 분야에서 성과에 초점을 맞추면서 협력 국가의 제도와 공공 부분을 활용하지 않고 NGO나 국제기구들을 활용한 것과는 대조가 된다. 


\section{IV. 뉴딜 시범사업의 이행 및 평가}

$\mathrm{IDPS}$ 와 INCAF는 뉴딜의 효과적인 이행을 위해 아프가니스탄, 중앙아시아공화국, 라이베 리아, 콩고민주공화국, 시에라리온, 남수단, 동티모르 등 7 개 국가가 시범 국가로 선정하였다. 이들 취약국가와 협력을 효과적으로 진행하기 위해 아프가니스탄-영국, 덴마크, 네덜란드, 라이 베리아-미국, 시에라리온-영국, 동티모르-호주, 남수단-EU, 영국 등 각각의 짝을 맺어 해당 취약국가에 포컬 포인트가 되는 공여국을 선정하여 효과성을 높이고자 하였다.

이 절에서는 뉴딜 시범사업을 수행하면서 가장 통합적 접근에 근접한 모습을 보여주었다고 평가되는 시에라리온을 중심으로 FOCUS의 관점에서 살펴보기로 한다. 시에라리온은 시범사업을 통해 PSG 지표를 구체화하고 공여국과 함께 진척 사항을 모니터하면서 사업을 추진하는 체계를 만들어 수행하고 있는 것으로 평가된다(UNDP 2015). 구체적으로 시에라리온은 뉴딜 시범 국가 중 가장 처음으로 2012년에 뉴딜의 FOCUS에 따른 취약성 평가(fragility assessment)를 실시하였 다. 이를 통해 시에라리온은 PSG 지표를 개발하였고, 이를 2013년 “Agenda for Prosperity”라는 국가계획에 통합하였다. 이후 2014년 영국과 상호책무성프레임워크(Mutual Accountability Framework, 이하 MAF)을 체결하였다(UNDP, 2015). 취약성 평가 결과 높은 청년실업과 성불평등, 높은 부패 수준, 인적 제도적 역량 부족과 낮은 수준의 경제적 거버넌스(특히, 재정관 리, 세입관리), 낮은 지역통합수준, 위기에 대한 높은 취약성 등이 시에라리온의 문제로 지적되 었다. 또한 2015년 1분기에는 유엔개발계획(United Nations Development Programme, $\mathrm{UNDP})$ 의 지원을 받아 취약성 평가를 보완했으나 에볼라 발병으로 제시된 초안은 최종적으로 마무리 되지 못했다(UNDP, 2015).

시에라리온 정부는 취약성 평가 결과를 기초로 한 국가발전계획인 "Agenda for Prosperity" 를 발표하였는데 이것은 'one Vision, one Plan'의 일환으로 준비되었다. 이 계획에 따르면 2035년까지 시에라리온을 중간 소득 국가로 발전시키며, 이를 위해 노력한다는 것이다. 구체적 으로는 천연자원의 내실 있는 관리, 경제적 성장동력의 다변화, 인적자원개발을 위한 교육, 민간의 경제활동을 위한 제도 개혁, 공공부문 역량 강화, 양성평등을 강조하고 있으며, 사회적 보호와 불평등의 축소, 그리고 고용과 노동 상황 개선을 목표로 제시하고 있다.

한편 영국 정부와 시에라리온 정부는 $\mathrm{MAF}$ 를 체결하였다. 이 협약은 시범사업을 수행하면서 서로에게 사업 진행사항을 설명하고 공유하는 것을 목적으로 하는데, 그 내용에는 원조수단에 대한 내용과 취약국의 국가계획에 대해 공여국이 어떤 방식으로 자원을 배분할 것인지에 대한 것도 공유하는 것으로 되어 있다(IDPS, 2015). 구체적으로 시에라리온 정부는 $\triangle$ "Agenda 
for Prosperity"에 따른 시범사업을 시행하기 위한 중기재정지출 계획과 공공투자계획을 세우 고, $\triangle$ 국제통화기금(International Monetary Fund, IMF)과 감사원 보고서의 권고에 따라 공공재정관리 및 통제 시스템을 강화하고, $\triangle$ 시에라리온의 개발수요에 맞는 재정지원을 하기 위해 정부의 세입 시스템 강화하며, $\triangle$ 비공식 행위자 (시민사회, 학계, 미디어, 민간)의 참여 증대와 의회의 모니터링과 감시를 강화할 것을 약속하였다.

시에라리온은 PSGs와 국가별 취약성 평가지표를 국가발전계획에 포함한 최초의 국가이다 (IDPS, 2014). 뉴딜 이행상황에 대한 모니터링에 따르면 시에라리온은 다른 시범 국가보다는 $\mathrm{PSG}$ 를 효과적으로 수립하였으며, 실제로 $\mathrm{MAF}$ 에 대시보드를 통해 뉴딜 이행상황을 보고하고 있다. 따라서 뉴딜 진행 상황 측면에서 긍정적인 평가를 받고 있다. $\mathrm{MAF}$ 의 모니터링을 위하여 시에라리온의 재정경제개발부(ministry of finance and economic development) 내의 개발 원조조정실(Development Aid Coordination Office, DAC)에서 원조의 흐름을 대시보드에 업데이트하고 있다(IDPS, 2015).

그렇다면 뉴딜 시범사업은 어떻게 평가할 수 있을까? 뉴딜 사업에 대한 평가는 기본적으로 시에라리온의 “Agenda for Prosperity” 와 같은 중장기 계획의 성공을 통해 평화정착과 국가 체제 구축에 달려 있다. 따라서 객관적인 평가에는 아직 시기적으로 이르다고 보인다. 그런데 TRUST의 관점에서 지금까지 진행사항에 대해 과정 평가를 진행할 수 있다. 투명성의 관점에 서 보면 시에라리온은 인터넷 페이지를 개설하여 진행사항을 공개하고 있으나 실제로 정보가 충분하지 않고 잘 작동하지 않는 상황이다. 위험의 공유 측면에서 영국은 취약국가에 대한 지원을 위해 세계은행 등과 공동기금을 마련하여 운영하고 있는데 이러한 점에서 위험공유에 대한 긍정적인 평가를 할 수 있다(IDPS, 2014a). 원조의 예측가능성에서도 뉴딜 사업을 통해 상당한 진천이 있는 것으로 평가된다. INCAF 등은 갑작스러운 위기에 대응한 인도주의적 지원을 신속히 할 수 있도록 정책 기제를 구축하고 있으며, 시에라리온에서 에볼라 바이러스가 발생했을 때 신속한 지원을 할 수 있었다.

뉴딜 사업 진행에 대한 과정 평가로서 가장 핵심적인 내용은 뉴딜을 통해 취약국가에 대한 재정지원이 효과적으로 이루어졌으며, 이를 통해 국가의 행정체제가 효과적으로 작동하도록 기여했는가이다. 시에라리온의 경우에는 이러한 질문에 긍정적으로 답을 할 수 있다. <그림 $1>$ 에서 보는 바와 같이 시에라리온에 대한 지원 규모는 다른 국가들에 비해 높은 수준에서 유지되고 있음을 알 수 있다. 
〈그림 1〉 취약국에 대한 예산 지원 규모

(단위: 백만 달러)

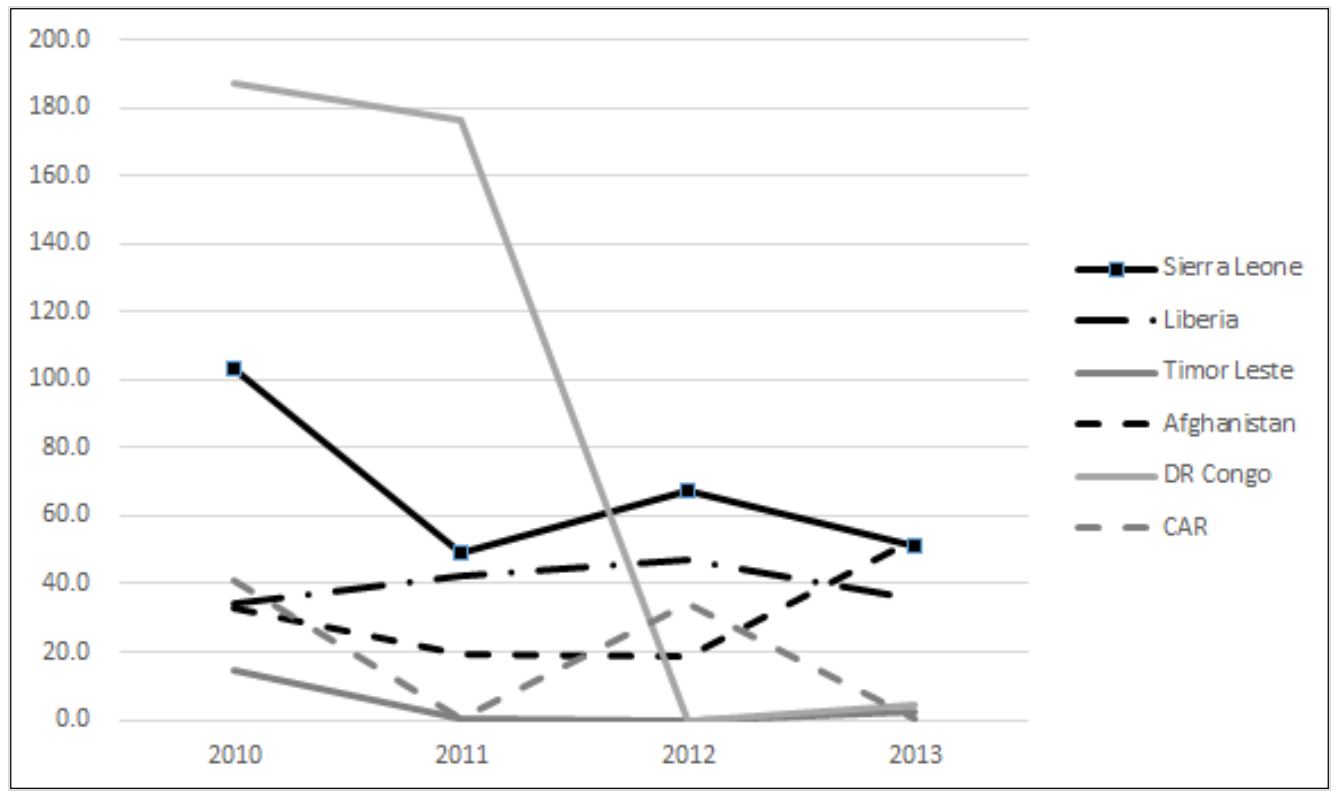

출처: $\mathrm{OECD}$, creditor reporting system 


\section{V. 결론 및 정책적 시사점}

뉴딜은 취약국가를 대상으로 한 국제개발협력에서 정치, 행정, 안보의 측면을 강조하는 새로 운 접근법을 기초로 수행된 사업이다. 국제개발협력 분야에서 가장 어려운 협력 상대자인 취약 국가의 발전을 위해서는 지금까지 초점을 맞추어온 경제·사회발전으로는 부족하고 평화구축과 국가체제 구축이라는 정치적이고 행정적인 발전이 필수적이라는 문제의식에서 출발하고 있는 것이다. 또한 취약국가들이 $\mathrm{g} 7+$ 라는 국제적 그룹을 만들고 이들과 OECD-INCAF가 IDPS라 는 협의기구를 통해 공여국과 취약국가들이 협력하고 상호 책임성을 인정하며 사업을 수행한다 는 사업방식도 매우 의미가 있는 것이라고 평가된다.

이 글에서는 취약국가라는 문제의식이 출발한 배경에서 개념 정의, 취약성의 원인과 취약국 가 발전을 위한 정책적 필요사항 등에 대해 논의하였으며, 이를 위한 국제사회의 논의와 정책적 노력을 검토하였다. 특히 시에라리온의 뉴딜 사업을 사례로 하여 취약국가에 대한 뉴딜의 사업 방식인 FOCUS와 TRUST의 관점에서 이행사항에 대한 과정 평가를 간략히 시도하였다. 시에라리온의 뉴딜 사업은 상당히 효과적으로 진행된 것으로 평가되나, 아직 중장기적 성과를 창출하기에는 시간이 부족하다는 객관적 평가를 내릴 수 있다.

취약국가에 대한 지원은 앞으로도 계속 추진되어야 하며, 이에 대한 보다 구체적이고 직접적 인 한국의 정책적 대안도 마련하는 것이 시급하다. 특히 취약국가에서 효과적인 개발성과가 $\mathrm{SDGS}$ 의 성공적인 달성을 위해서 반드시 필요한 과제이기 때문이다. 그러나 최근 국제사회의 정치적 변화는 향후 개발협력 분야의 정책적 환경이 매우 불확실하게 할 가능성이 높아 보인다. 미국 트럼프 행정부의 미국 우선주의로 개발협력 분야에 대한 정책적 우선순위를 낮출 가능성이 매우 크고, 유럽에서도 지금까지의 긴축재정에서 유지되었던 국제개발협력 예산이 축소할 가능 성이 높기 때문이다. 취약국가 지원을 위한 뉴딜의 핵심이 취약국가 시스템을 활용한 지원이라 고 본다면, 이러한 형태의 지원이 시행되기 점점 더 어려운 상황을 맞이하게 될 것으로 보인다.

그런데 국제사회에서 신흥 공여국으로 성장해온 한국의 관점에서는 이제 취약국가에 대한 지원을 위한 뉴딜과 같은 사업에서 중요한 역할을 담당해야 한다는 책임을 느끼지 않을 수 없다. 한편으로 지금까지 경제·사회 분야에 집중해오던 한국의 국제개발원조가 뉴딜과 같이 정치적, 행정적, 국제정치적 성격이 강한 분야에서 효과적으로 집행되려면 이에 대한 철저한 준비와 계획에 기초하여 치밀한 사업수행이 이루어져야 할 것이다. 특히 뉴딜 사업은 협력 상대국인 취약국가의 취약성 평가와 이에 따른 중장기 발전계획의 수립 및 공유, 이에 따른 재정지원 및 행정지원 등이 수행되어야 하는 고도의 일관된 행정, 재정사업으로서 이에 대한 
전문적 사업수행과 전문가의 역할이 필수적이다. 이러한 점에서 이 분야에서 아직 경험이 많이 축적되지 않은 한국은 특정 취약국가와 협력하는 포컬 포인트로 역할을 처음부터 수행하기보다 는 이미 맺어진 짝에 동참하는 것도 고려해볼 만하다.

결론적으로 취약국가에 대한 지원은 공여국으로서 고도의 전문성과 재정적 역량을 필요로 하는 한편, 이에 대해 효과적인 정책수행을 한다면 국제개발협력 분야에서 한국의 위상을 한 단계 높이는 기회로 작용할 것으로 보인다. 


\section{〈참고문헌〉}

권혁주·이환성·배재현. 2011. 『한국 ODA의 분쟁 및 취약국 지원방안』. 정책연구 201101-003. 성남: 한국국제협력단.

배재현·노우영. 2012. "국제사회의 취약국 지원원칙과 한국의 취약국 지원방안 마련을

위한 탐색적 연구."『행정논총』제50권 1호:279-301.

배재현·노우영·권혁주. 2010. "취약국 지원을 위한 범국가적 접근방안 연구: 국제개발협

력위원회 사례를 중심으로."『정책분석평가학회보』제22권 4호:69-93.

Berttoli, S \& Elisa Ticci. 2012. “A fragile guideline to development assistance." Development Policy Review vol.30(2):211-30.

Bertocchi, G., \& Guerzoni, A.. 2012. "Growth, history, or institutions What explains state fragility in sub-Saharan Africa?" Journal of Peace Research vol.49(6):769-83.

Dollar, D. \& Levin, V., 2006. “The Increasing Selectivity of Foreign Aid, 19842003.” World Development vol.34(12):2034-46.

Engberg-Pedersen, L., Andersen, L. \& Stepputat, F.. 2008. "Fragile Situations, Current Debates and Central Dilemmas." Copenhagen: Danish Institute for International Studies.

Feeny, S., Posso, A., \& Regan-Beasley, J.. 2015. "Handle with care: Fragile States and the Determinants of Fragility." Applied Economics vol.47(11): 1073-85.

Grimm, S.. 2014. "The European Union's ambiguous concept of 'state fragility'." Third World Quarterly vol.35(2):252-67.

IDPS. 2015. "Lessons Learning Best Practice Paper: Using New Deal Framework in Response and Recovery (Draft) Document 04.” International Dialogue Steering Group Meeting. 25 May 2015, Abidjan, Côte d’Ivoire. . 2014. “New Deal Monitoring Report 2014." International Dialogue Working Group on New Deal Implementation.

. 2013. "Peacebuilding and Statebuilding Indicators - Progress, Interim List and next steps.” Proceedings from 3rd International Dialogue Global 
Meeting "The New Deal: Achieving Better Results and Shaping the Global Agenda,” 19 April 2013, Washington, D.C.

. 2011a. "New Deal for Engagement in Fragile States." International Dialogue on Peacebuilding and Statebuilding (IDPS).

. 2011b. "The Monrovia Roadmap on Peacebuilding and Statebuilding."

International Dialogue on Peacebuilding and Statebuilding (IDPS).

. 2010a. "Dili Declaration: A New Vision for Peacebuilding and Statebuilding." International Dialogue on Peacebuilding and Statebuilding (IDPS).

. 2010b. "The International Dialogue on Peacebuliding and Statebuilding," contribution by Timor-Leste.

Nussbaum, T., Zorbas, E., \& Koros, M. 2012. “A new deal for engagement in fragile states." Conflict, Security \& Development vol.12(5):559-87.

OECD. 2015a. "States of Fragility 2015: Meeting Post-2015 Ambitions." Paris: OECD.

. 2007. "Principles for Good International Engagement in Fragile States and Situations." Paris: OECD.

UNDP. 2015. "New Deal Support Facility: Implementation Overview." New York: UNDP.

Yin, Robert. 1989. Case Studies Research: Design and Methods. New York: Sage Publication. 